\title{
MAGE-A is frequently expressed in triple negative breast cancer and associated with epithelial-mesenchymal transition
}

\author{
H. WANG ${ }^{1}$, M. SANG ${ }^{1}$, C. GENG ${ }^{2}$, F. LIU 1 , L. GU 1 , B. SHAN ${ }^{1, *}$ \\ ${ }^{1}$ Research Center, The Fourth Hospital of Hebei Medical University, Jiankang Road, Shijiazhuang, Hebei, 050017, PR China; ${ }^{2}$ Department of \\ Breast Cancer Center, The Fourth Hospital of Hebei Medical University, Jiankang Road, Shijiazhuang, Hebei, 050017, PR China
}

*Correspondence: baoenshan1962@163.com

Received June 10, 2015 / Accepted August 17, 2015

\begin{abstract}
Epithelial-mesenchymal transition (EMT) is a crucial step in tumor metastasis. Triple negative (TN) breast cancer, a high metastasis phenotype, has been verified to be associated with EMT. Melanoma associated antigen-A (MAGE-A) is exclusively expressed in cancers with high aggressiveness as well as unfavorable prognosis and likely to be associated with EMT of triple negative breast cancer (TNBC). The aim of the study is to analyze the expression profile of MAGE-A in breast cancer and the correlation between MAGE-A and EMT of TNBC. Immunohistochemistry (IHC) was performed to assess the prevalence of MAGE-A, vimentin, E-cadherin and $\beta$-catenin in breast cancer tissues and correlate them with clinical pathological parameters. The association between MAGE-A and EMT markers was also evaluated. Scratch assay and transwell invasion assay were carried out to evaluate the impact of MAGE-A down-regulation on migration and invasion of the breast cancer cells. Real-time PCR was also conducted to evaluate alterations in EMT markers with decrease in MAGE-A. The results showed that MAGE-A was absent in normal tissue but expressed in tumor samples with the incidence of $49.17 \%(P=0.008)$. MAGE-A staining was higher in TNBC $(76.47 \%, 13 / 17)$, followed by HER-2(+) $(53.85 \%, 7 / 13)$ and Luminal set $(43.33 \%$, 39/90), and it was significantly correlated with ER (-), PR (-), HER-2 (-), lymph nodes involvement and higher histological grade $(P<0.05)$. E-cadherin-positivity was frequent in Luminal set $(94.44 \%, 85 / 90)$ and linked to ER $(+)$, negative lymph nodes and lower histological grade $(P<0.05)$. Vimentin expression was often observed in TNBC $(70.59 \%, 12 / 17)$ and ER $(-)$, PR $(-)$, lymph nodes $(+)$ groups $(P<0.05)$. Expression of $\beta$-catenin was prevalent in Luminal set $(93.33 \%, 84 / 90)$ and correlated with ER $(+)$, PR $(+)$ and lower histological grade $(P<0.05)$. MAGE-A was inversely associated with E-cadherin $(P=0.011)$ and $\beta$-catenin $(P=0.048)$ but expressed in the same trend with vimentin $(P=0.000)$. Migration and invasion of MDA-MB-231 were inhibited when MAGE-A decreased. Increase in epithelial markers and decline in mesenchymal indicators were also seen with MAGE-A reduction. Snail, Slug, ZEB1 and ZEB2 were also down-regulated. In conclusion, MAGE-A may be responsible for high aggressiveness and EMT of TNBC and can be a new choice for targeted therapy.
\end{abstract}

Key words: MAGE-A, breast cancer, triple negative breast cancer, epithelial-mesenchymal transition

According to the latest epidemiological data, primary breast cancer is the second most common cancer in the world and, by far, the most frequent cancer among women with an estimated 1.67 million new cancer cases diagnosed in 2012 (25\% of all cancers). According to the expression profile of estrogen receptor (ER), progesterone receptor (PR), human epidermal growth factor receptor-2 (HER-2) and Ki-67, breast cancer is mainly divided into four categories including: Luminal A-type, Luminal B-type, HER-2 overexpression type and basal-like type. Triple negative breast cancer (TNBC) accounting for about $80 \%$ of basal-like type is of higher histological grade and higher incidence of distant metastasis after initial treat- ment [1]. Although marked advances in early diagnosis and management of breast cancer cases, survival time of TNBC cases apart from medullary and adenoid cystic carcinoma, remains to be shorter as a consequence of metastasis to distant organs at an early time [2-6]. Thus, discovery of mechanism for metastasis and new targeted oncogenes are pivotal for anticancer therapy.

Epithelial-mesenchymal transition (EMT) is a transient process which is confirmed to be a major player in physiological and pathological processes. It is characterized with loss of epithelial traits including E-cadherin, Claudins, Occludin and acquisition of mesenchymal features, such as fibronectin, 
vimentin, $\mathrm{N}$-cadherin and matrix metalloproteinases (MMPs) [7]. This process is regulated by several transcription regulators including Snail (Snaill and Snail2), Zinc Finger E-box Binding Homeobox 1 (ZEB1) and 2 (ZEB2) and basic helix-loop-helix (bHLH) (E47 and Twist) families [8]. EMT has been accepted as a contributor to tumor progression, metastasis and drug resistance [9-10]. What's more, it has been proved that EMT is highly linked to aggressiveness of TNBC [11-14].

Cancer/testis antigens (CTA), a series of tumor associated antigens, are exclusively expressed in diverse tumor entities [15] but silent in normal tissues except for testicular germ cells and placenta [16-18]. Due to the restricted expression pattern and their capability to elicit immune responses, CTAs are counted as ideal targets for immunotherapy in human malignancy [19-20]. Melanoma associated antigen (MAGE), a member of CTA, is composed of type I (MAGE-A, MAGE-B, and MAGE-C) and type II (MAGE-D) family based on variation in gene structure and tissue-specific expression pattern [21]. MAGE-A consists of 12 homologous genes (MAGE-A1 to -A12) located in the q28 region of chromosome X [21]. Accumulating evidence showed that MAGE-A expression is accused for tumor growth and progress [23-26]. Moreover, MAGE-A expression is detected frequently in TNBC patients [27].

Above all, we speculate that MAGE-A may contribute to EMT of TNBC. In order to address this issue, immunohistochemistry (IHC) was performed to investigate the expression pattern of MAGE-A and EMT markers (vimentin, E-cadherin, $\beta$-catenin) in breast cancer tissues and correlate them with clinicopathologic parameters. Also, we evaluated the association between MAGE-A and EMT markers. Then, MAGE-A expression was knocked down to detect its influence on invasive and migratory potential and alterations in EMT markers of triple-negative breast cancer cell line MDA-MB-231, known to be highly metastatic. The results showed that MAGE-A expression was more prevalent in TNBC patients and associated with indicators suggestive of unfavorable prognosis. Furthermore, MAGE-A could regulate EMT of MDA-MB-231 partially.

\section{Patients and methods}

Patients and samples. Samples including 120 cancer tissues and 10 tumor-free tissues were obtained from a consecutive series of 120 female breast cancer patients who underwent mastectomy at the Center of Breast Cancer of The Fourth Hospital of Hebei Medical University (Shijiazhuang Hebei), over a six-month period (2013.9-2014.2). All cases were diagnosed with breast cancer via needle biopsies examination. None of them obtained chemotherapy and radiotherapy before operation. Postoperative pathological examination of primary resected tumors was performed at Department of Pathology of that hospital. The clinicopathological indexes were collected including: age, menstrual status, histological type and grade, tumor size, lymphatic metastasis, blood vessel invasion, TNM stage, ER, PR, Topoisomerase II (TOPOII), Ki-67, p53 and HER-2. All patients provided written informed consent before enrollment. The study was approved by the Medical Ethics Committee of the Fourth Hospital of Hebei Medical University.

Cell lines and transfection. Triple negative breast cancer cell line MDA-MB-231, obtained from Research Cancer of the Forth Hospital of Hebei Medical University, was cultured in RPMI-1640 medium supplemented with $10 \%$ fetal bovine serum, penicillin $(100 \mathrm{U} / \mathrm{ml})$, and streptomycin $(100 \mu \mathrm{g} / \mathrm{ml})$ at $37^{\circ} \mathrm{C}$ in $5 \% \mathrm{CO}_{2}$. MAGE-A siRNA (h) (SC-35843, SANTA CRUZ BIOTECHNOLOGY, USA), a pool of 6 different siRNA duplexes, was transiently transfected into MDA-MB-231 cells using FuGENE HD (E2311, Promega USA). MAGE-A siRNA (h) sequence was as follows: sense: 5' - AGUCACACAUAGUGCUGUUTT-3', antisense: 5'-AACAGCACUAUGUGUGACUTT-3'; sense:5' - AGAGGGAGUCUGAGCAUGATT-3', antisense: 5'-UCAUGCUCAGACUCCCUCUTT-3'; sense: 5'-CUACCCAUCCCUUUAUGAATT-3', antisense: 5'-UUCAUAAAGGGAUGGGUAGTT-3'; sense:5'-GGAAGCACUUGAUGAGAAATT-3', antisense: 5'-UUUCUCAUCAAGUGCUUCCTT-3'; sense: 5'-CCCAAGAUAUACUACAUGATT-3', antisense: 5'-UCAUGUAGUAUAUCUUGGGTT-3'; sense: 5'-CCAGAAGUGAGAUAGAUGATT-3', antisense: 5'UCAUCUAUCUCACUUCUGGTT-3'.

Immunohistochemistry. Briefly, paraffin-embedded tissues were cut as $4 \mu \mathrm{m}$ sections and then deparaffinized, rehydrated and incubated in EDTA (Ethylene Diamine Tetraacetic Acid, $\mathrm{pH}$ 9.0) at $100^{\circ} \mathrm{C}$ for 4 minutes. Next, the sections were stained with MAGE-A primary antibody (6C1 mAb, 1:50, Santa Cruz Biotechnology, USA) which can react with MAGE-A1, 2, 3, 4, 6, 12, vimentin antibody (1:500, Santa Cruz Biotechnology, USA), E-cadherin (1:250, Biosynthesis, China), $\beta$-catenin (1:250, Biosynthesis, China) and corresponding secondary antibody. Visualization was done after incubation with DAB (3, 3'-Diaminobenzidine Tetrahydrochlorid, ZSGB-BIO, China). Testis tissue was used as the positive control, tumor-free breast tissue was stained as negative control. Figures were taken in $200 \times$ and $400 \times$ magnifications to document the positively stained areas. All samples were evaluated by two observers.

Scoring. MAGE-A: The detection of nuclear and /or cytoplasmic staining in any percentage of tumor cells was considered positive for MAGE-A. Complete absence of staining was considered negative for MAGE-A expression [28].

E-cadherin, $\beta$-catenin: Expression was scored by assessing the stain intensity and the percentage of stained cells in the tumors. Staining intensity was scored as 0 (no staining), $1+$ (weak), $2+$ (medium), or $3+$ (strong). The percentage of stained cells was classified as follows: $1,0 \%$ to $10 \%$ stained cells; $2,11 \%$ to $50 \%$ stained cells; $3,50 \%$ stained cells or greater. The final score was obtained by multiplying the two scores. Cases with a score of 0 to 4 were interpreted as (-), and those with a final score of 5 to 9 were classified as (+) [29]. 
Vimentin: Any distinct positive staining of the tumor cell cytoplasm with the vimentin antibody was considered as positive vimentin expression [30].

RNA extractions and RT-PCR. Total RNA of cultured cells was isolated using the TRNzol Reagent (DP405-02, TIANGEN, China). The RNA concentration was routinely measured and its quality was determined by agarose gel electrophoresis stained with GoTaq Green Master Mix (A5001, Promega, USA). RNA was reverse transcribed to cDNA using RevertAid First Strand cDNA Synthesis Kit (A5000, Promega, USA). For RT-PCR, the primers were designed as Table 1. GAPDH was used as reference gene and its sequence was listed in Table 1 . The amplification conditions were: pre-degeneration at $95^{\circ} \mathrm{C}$ for $5 \mathrm{~min}$ followed by 35 cycles of degeneration at $95^{\circ} \mathrm{C}$ for $30 \mathrm{sec}$, annealing for $30 \mathrm{sec}$ at various temperatures depending on the targeted genes and extension at $72^{\circ} \mathrm{C}$ for $30 \mathrm{sec}$ followed by the final extension at $72^{\circ} \mathrm{C}$ for $7 \mathrm{~min}$. PCR products were confirmed by agarose gel electrophoresis. The bands were visualized and

Table 1. Sequences of Primers for PCR

\begin{tabular}{|c|c|c|}
\hline Genes & Primer Sequence & $\begin{array}{l}\text { Annealing } \\
\text { Tempera- } \\
\text { ture }\left({ }^{\circ} \mathrm{C}\right)\end{array}$ \\
\hline MAGE-A1 & $\begin{array}{l}\text { Forward: 5'-GGAGCACCAAGGAGAAGA-3' } \\
\text { Reverse: 5'-TGATGGTAGTGGGAAAGG-3' }\end{array}$ & 57 \\
\hline MAGE-A2 & $\begin{array}{l}\text { Forward: 5'-AAGTAGGACCCGAGGCACTG-3' } \\
\text { Reverse: 5'-GAAGAGGAAGAAGCGGTCTG-3' }\end{array}$ & 62 \\
\hline MAGE-A3 & $\begin{array}{l}\text { Forward: 5'-CAACGAGCGACGGCCTGAC-3' } \\
\text { Reverse: 5'-CCACTGGCAGATCTTCTCCTTC-3' }\end{array}$ & 59 \\
\hline MAGE-A4 & $\begin{array}{l}\text { Forward:5'- GAGCAGACAGGCCAACCG-3' } \\
\text { Reverse:5'-AAGGACTCTGCGTCAGGC-3' }\end{array}$ & 65 \\
\hline MAGE-A6 & $\begin{array}{l}\text { Forward: 5'-GGAAGGTGGCCAAGTTGGTTC-3' } \\
\text { Reverse: 5'-CCAGCTGCAAGGAATCGGAAG-3' }\end{array}$ & 56 \\
\hline MAGE-A12 & $\begin{array}{l}\text { Forward: 5'-GGAAGATGGCTGAGTTGG-3' } \\
\text { Reverse:5'-AGGCAGGTGACAAGGATG-3' }\end{array}$ & 53 \\
\hline Vimentin & $\begin{array}{l}\text { Forward:5'-AAAGTGTGGCTGCCAAGAAC-3' } \\
\text { Reverse: 5'-AGCCTCAGAGAGGTCAGCAA-3' }\end{array}$ & 58 \\
\hline E-cadherin & $\begin{array}{l}\text { Forward: 5'-GGCCAGGAAATCACATCCTA-3' } \\
\text { Reverse: 5'-GGCAGTGTCTCTCCAAATCC-3' }\end{array}$ & 58 \\
\hline $\mathrm{N}$-cadherin & $\begin{array}{l}\text { Forward: 5'-CATCATCATCCTGCTTATCCTTGT-3' } \\
\text { Revers: 5'-GGTCTTCTTCTCCTCCACCTTCTT-3' }\end{array}$ & 57 \\
\hline$\beta$-catenin & $\begin{array}{l}\text { Forward:5'- GTACGTCCATGGGTGGGACA-3' } \\
\text { Reverse:5'-GGCTCCGGTACAACCTTCAACTA-3' }\end{array}$ & 65 \\
\hline Snail & $\begin{array}{l}\text { Forward:5'- GCTGCAGGACTCTAATCCAGA-3' } \\
\text { Reverse:5'- ACTTCCGGAGGTGGGATG-3' }\end{array}$ & 59 \\
\hline Slug & $\begin{array}{l}\text { Forward:5'- ACAGCGAACTGGACACACAT-3' } \\
\text { Reverse:5'- GATGGGGCTGTATGCTCCT -3' }\end{array}$ & 60 \\
\hline ZEB1 & $\begin{array}{l}\text { Forward: 5'-TGTTACCAGGGAGGAGCAGT-3' } \\
\text { Reverse:5'-GCTTCATCTGCCTGAGCTTC-3' }\end{array}$ & 59 \\
\hline ZEB2 & $\begin{array}{l}\text { Forward: 5'-ACAAGCCAGGGACAGATCA-3' } \\
\text { Reverse: 5'-GCCACACTCTGTGCATTTGA-3' }\end{array}$ & 59 \\
\hline MMP9 & $\begin{array}{l}\text { Forward: 5'-GCACCACCACAACATCACCTA-3' } \\
\text { Reverse: 5'-GGACCACAACTCGTCATCGT-3' }\end{array}$ & 58 \\
\hline GAPDH & $\begin{array}{l}\text { Forward:5'-AACGGATTTGGTCGTATTG-3' } \\
\text { Reverse:5'-GCTCCTGGAAGATGGTGAT-3' }\end{array}$ & 58 \\
\hline
\end{tabular}

analyzed by GBOXEF2 GENESys (Syngene Image Software, Cambridge, UK).

Real-time qRT-PCR. Briefly, total RNA was extracted from cells, and cDNA was reverse-transcribed using GoScript ${ }^{\mathrm{TM}}$ Reverse Transcription System (A5000, Promega, USA). Quantitative real-time RT-PCR (qRT-PCR) was carried out in quadruplicate using GoTaq qPCR Master Mix (A6002, Promega, USA) via 7500 FAST Real-Time PCR system (Applied Biosystems, USA). PCR was performed using the following primers displayed in Table 1. Samples underwent three-step amplification for 35 cycles: denaturation at $95^{\circ} \mathrm{C}$ for $30 \mathrm{sec}$, the annealing temperature depending on different primers listed in the table for $30 \mathrm{sec}$, and extension at $72^{\circ} \mathrm{C}$ for $30 \mathrm{sec}$. The CT values for the tested genes were normalized to GAPDH and relative expression represented as $2^{-\Delta \Delta C T}$.

Scratch assay. $5.0 \times 10^{5}$ cells were evenly seeded in 6-well plates per well and incubated until they reached confluency. After transfection with siRNA for $24 \mathrm{~h}$, confluent cell layers were washed with PBS then scratched perpendicularly with a sterile $200 \mu \mathrm{l}$ pipette tip to generate homogeneous wounds in each well. After washing with PBS, the cells were incubated with non-serum medium for another $24 \mathrm{~h}$. The changes of the migratory distance were observed and the images were taken via microscope at $100 \times$ magnifications (TE2000-U; Nikon, Japan). The movement distance of the cells across the wound was measured using NIS-Elements F 2.30 (Nikon, Japan). The results were represented as relative migration rate (\%). The experiment was repeated for six times.

Transwell invasion assay. After siRNA transfection for $24 \mathrm{~h}, 1 \times 10^{5}$ cells in serum-free medium were seed in the upper chamber on the $8.0 \mu \mathrm{m}$ porous polycarbonate membrane (Coring Incorporated Costar, 3422, USA) coated with Matrigel (BD354248, BD, USA). The lower chamber was filled with medium containing $10 \%$ fetal bovine serum. After $24 \mathrm{~h}$ incubation, the cells from the upper surface of the filter were removed with cotton tips, and the cells that invaded to the underside of the filter were fixed in $4 \%$ paraform and stained with crystal violet. Images were captured by microscope (TE2000-U; Nikon, Japan) at $200 \times$ magnification. Cells in 10 random microscopic fields were counted and presented as the average number of cells / field of view.

Statistics. Statistical analyses were performed using statistical software of SPSS 16.0 (Inc.; Chicago, USA). The positive rate of MAGE-A and EMT markers, and the association between them and clinical pathological indicators were analyzed by Pearson's $\chi 2$ test or Continuity Corrected Pearson's $\chi 2$ test or Fisher's exact test. The Student's t test was used to compare differences between groups concerning parametric variables. $P$-value $<0.05$ was considered statistically significant.

\section{Results}

Clinico-pathological characteristics. The clinicopathological characteristics of the subjects are listed in Table 3. All cases in this study were female aged from 28 to 83 years. 59 out 
of all cases were premenopausal whereas 61 patients were postmenopausal. The tumor size of 64 patients were $\leq 2 \mathrm{~cm}$, while others were larger than $2 \mathrm{~cm}$. Positive axillary lymph nodes were found in 68 cases, whereas 42 patients were found to be negative. Patients in stage I were 37, stage II 58 and stage III 25 . Most of the cases $(92 / 120)$ were invasive ductal carcinomas. 46 patients $(46 / 120)$ had vascular invasion. 56 cases $(56 / 120)$ were p53-positive. The majority of the subjects $(107 / 120)$ had TOPOII expression. 37 cases were in grade I, 58 patients were in grade II and only 25 cases were in grade III.

Subgroups of breast cancers were classified by ER, PR, Ki-67 and HER-2. The latest classification on breast cancer proposed in the consensus at St. Gallen, 2013 [31-32] including: luminal A (ER+, PR $\geq 20 \%$, HER-2-, Ki-67<14\%), luminal B (HER-2 negative : ER+, HER-2 -, Ki-67 $\geq 14 \%$ or $\mathrm{PR}<20 \%$; HER-2 positive: ER+, HER-2+, any level of Ki-67 and PR), HER-2 over-expression (HER-2+, ER-, PR-) and basal-like (mainly composed by TN: ER -, PR -, HER-2-). We mainly divided all the subjects into three groups according to this criterion: Luminal set including Luminal A (12/120, 10.00\%) and $B(78 / 120,65.00 \%)$ type accounted for $75.00 \%(90 / 120)$ of all. About $10.83 \%$ cases (13/120) fell into HER-2 (+) set. The proportion of TNBC was $14.17 \%$ (17/120).

MAGE-A was exclusively expressed in neoplastic tissue and frequently seen in TNBC by IHC. To delineate MAGE-A expression pattern in breast cancer, we analyzed MAGE-A expression by IHC in tissue sections from 120 patients and 10 normal mammary gland samples. As shown in Figure 1, MAGE-A gene expression was observed in cytoplasm and/ or nucleus of cancer cells. About 49.17\% (59/120) of all cases were MAGE-A-positive, while none of the tumor-free samples was stained with MAGE-A antibody $(P=0.008)$ (Figure 2). MAGE-A was positively expressed in normal testis tissues as documented in Figure 3. As for breast cancer subtypes, MAGE-A staining was observed in 39 cases $(43.33 \%, 39 / 90)$ belonging to Luminal set. The prevalence of MAGE-A in HER-2(+) and TN set were 53.85\% (7/13) and 76.47\% (13/17), respectively. The difference of MAGE-A positivity among the subgroups was significant $(P=0.041)$ (Table 2$)$. Representative positive staining case of each set was shown in Figure 1.
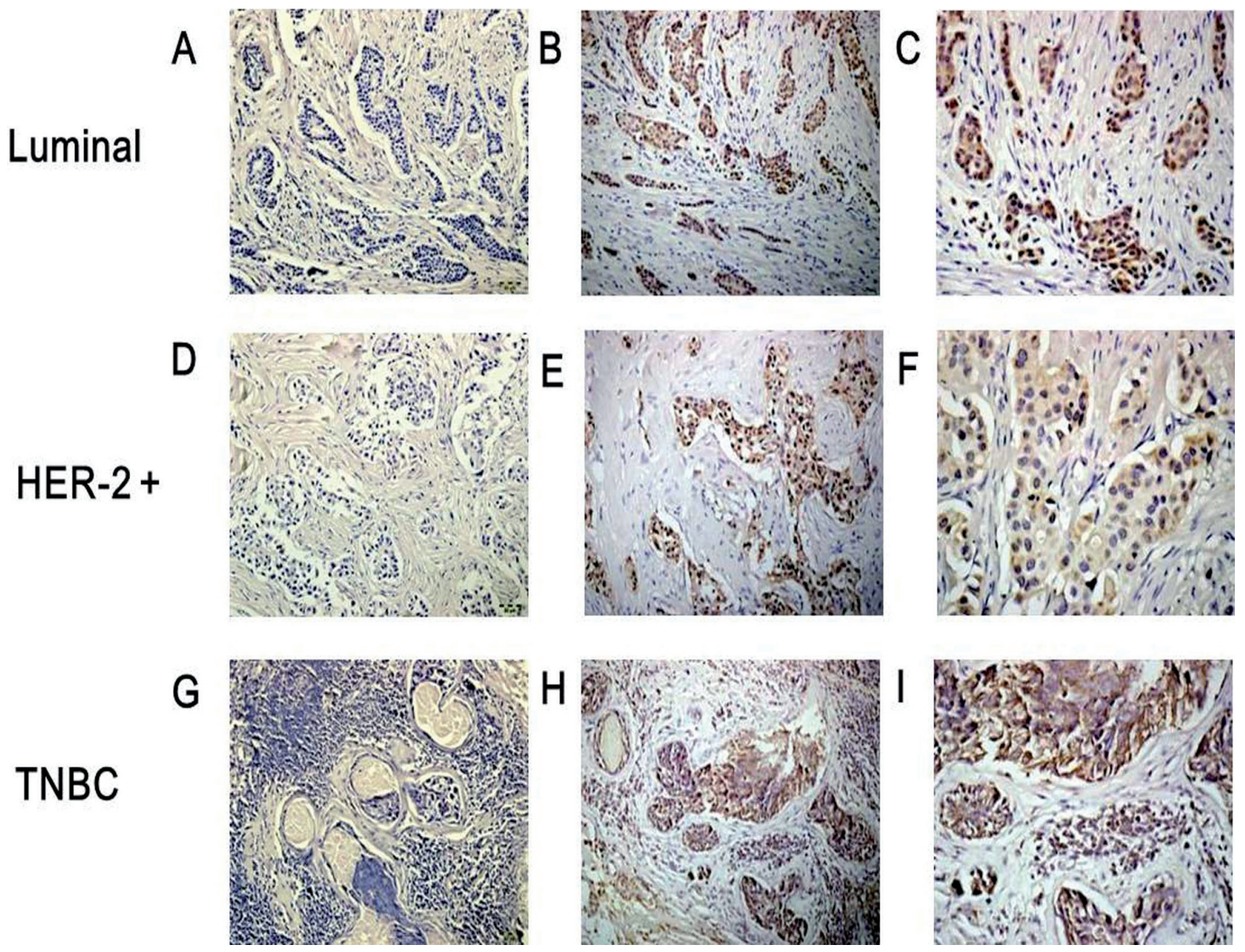

Figure 1. Immunohistochemical detection of MAGE-A expression in breast cancer cases. A. Negative expression of MAGE-A in Luminal set $(\times 200)$ B, C. MAGE-A staining in breast cancer tissue of Luminal set $(\times 200, \times 400)$ D. Negative expression of MAGE-A in HER-2 + set $(\times 200)$ E, F. MAGE-A staining in HER-2 $(+)$ set $(\times 200, \times 400)$ G. Negative expression of MAGE-A in TN set $(\times 200) \mathrm{H}, \mathrm{I}$. MAGE-A staining in TN set $(\times 200, \times 400)$. 

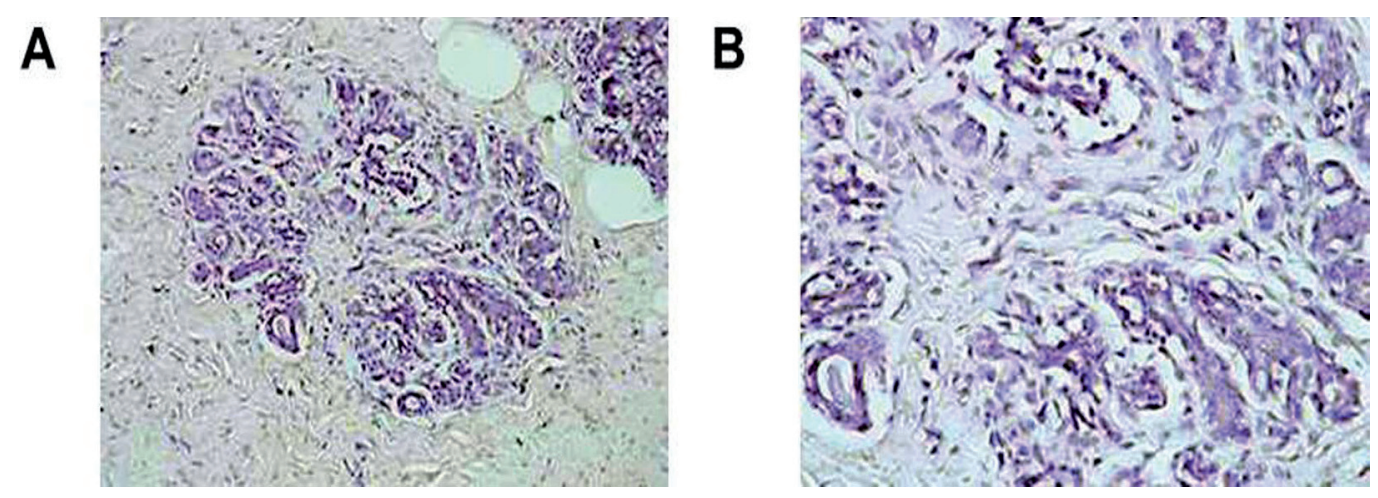

Figure 2 A, B. MAGE-A expression in normal breast tissue $(\times 200, \times 400)$.
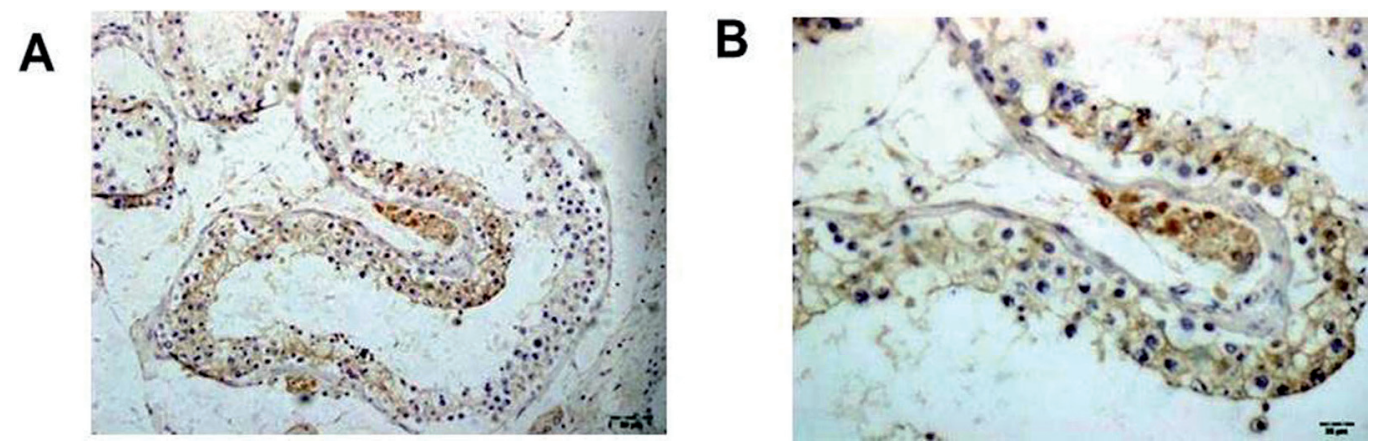

Figure 3 A, B. MAGE-A expression in normal testis tissue, it is mainly expressed in primary spermatocytes and spermatogonia $(\times 200, \times 400)$.

MAGE-A expression was concerned with tumor aggressiveness and metastasis. To assess the role of MAGE-A in breast cancer pathogenesis, we investigated the distribution of MAGE-A in different pathological indexes of the patients. As shown in Table 3, MAGE-A was significantly associated with ER (-) $(P=0.027)$, PR (-) $(P=0.000)$ and HER-2 $(-)(P=0.017)$, and this might be a reason for the high incidence of MAGE-A in TN subset. MAGE-A was more prevalent in patients with higher histological grade (grade II and III) $(P=0.001)$ and axillary lymphatic metastasis cases $(P=0.000)$ indicating that MAGE-A is highly responsible for cancer metastasis and aggressiveness. There was no correlation was established between MAGE-A expression and other parameters $(P>0.05)$. Accordingly, MAGE-A has link with indicators predicting bad outcomes, and it is exactly responsible for aggressiveness of malignant phenotypes.

Decrease in epithelial markers and elevation in mesenchymal markers were observed in TNBC. To assess the expression profile of EMT markers in different breast cancer subtypes, IHC was performed to analyze vimentin, E-cadherin and $\beta$-catenin expression in subjected cancerous cases (Table 2). We observed that vimentin was expressed in cytoplasm. It was positive in $41(41 / 120)$ of all cases with the highest prevalence in TN set $(12 / 17,70.59 \%)$ followed by HER-2 overexpression $(6 / 13,46.15 \%)$ and Luminal set $(23 / 90,25.55 \%)$, and the difference among the subtypes was statistically significant $(P=0.001)$. The staining of E-cadherin could be seen in membranous or cytoplasm in 105 samples

Table 2. Expression of MAGE-A and EMT markers in breast cancer tissue

\begin{tabular}{|c|c|c|c|c|c|c|c|c|c|c|c|c|c|}
\hline \multirow[t]{2}{*}{ Groups } & \multirow[t]{2}{*}{$\mathrm{N}$} & \multicolumn{2}{|c|}{ MAGE-A } & \multirow[t]{2}{*}{$P$} & \multicolumn{2}{|c|}{ vimentin } & \multirow[t]{2}{*}{$P$} & \multicolumn{2}{|c|}{ E-cadherin } & \multirow[t]{2}{*}{$P$} & \multicolumn{2}{|c|}{$\beta$-catenin } & \multirow[t]{2}{*}{$P^{a}$} \\
\hline & & + & - & & + & - & & + & - & & + & - & \\
\hline Luminal & 90 & 39 & 51 & 0.041 & 23 & 67 & 0.001 & 85 & 5 & $<0.001$ & 84 & 6 & $<0.001$ \\
\hline HER-2(+) & 13 & 7 & 6 & & 6 & 7 & & 11 & 2 & & 7 & 6 & \\
\hline TNBC & 17 & 13 & 4 & & 12 & 5 & & 9 & 8 & & 7 & 10 & \\
\hline
\end{tabular}

a Fisher's Exact Test 
(105/120, 87.50\%). Cases from Luminal set were more prone to be positive with E-cadherin $(85 / 90,94.44 \%)$, while patients in HER-2 overexpression $(11 / 13,84.61 \%)$ and TN group $(9 / 17$, $52.94 \%)$ were less in E-cadherin positivity $(P=0.000)$. $\beta$-catenin expression was mainly observed in cytoplasm and nucleus. It was expressed in 98 patients of all (98/120, 81.67\%), showing the higher positive rate in Luminal set $(84 / 90,93.33 \%)$ but less in HER-2 (+) set $(7 / 13,53.85 \%)$ and TNBC $(7 / 17$, $41.18 \%)(P=0.000)$. It was obvious that lower expression of epithelial markers and higher level of mesenchymal markers were frequently seen in TN-type predicting the existence of EMT in TNBC. Representative staining cases of EMT markers were shown in Figure 4.

Loss of epithelial markers and gain of mesenchymal markers indicated high tendency to metastasis and bad prognosis. To further our study in association between EMT and breast cancer subtypes, we analyzed the distribution of the EMT markers in related pathological indexes of patients. As shown in Table 3, E-cadherin was inversely linked to ER $(-)(P=0.000)$, positive lymph nodes $(P=0.012)$ and high histological grade $(P=0.009)$. Similarly, $\beta$-catenin expression was significantly related to ER-positive $(P=0.000), P R-p o s i t i v e ~(P=0.011)$ and low histological grade $(P=0.000)$. Instead, vimentin expression was more frequent in $\operatorname{ER}(-)(P=0.001), \operatorname{PR}(-)(P=0.000)$, lymph nodes $(+)$ cases $(P=0.009)$. There was no correlation established between EMT markers and other pathological parameters $(P>0.05)$. As such, the loss of epithelial markers and acquisition of mesenchymal markers demonstrated high tendency to metastasis and bad prognosis. Evidently, EMT is more prone to occur in TNBC characteristic with ER (-), PR (-) and HER-2 (-).
A

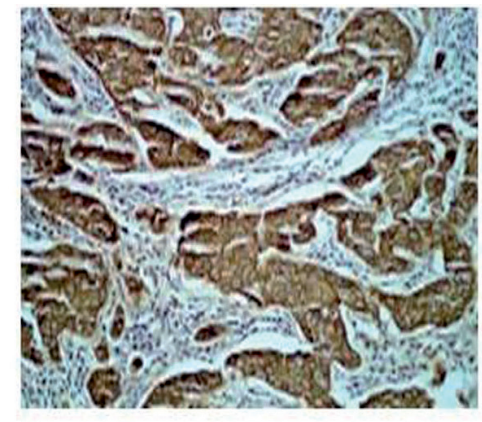

D

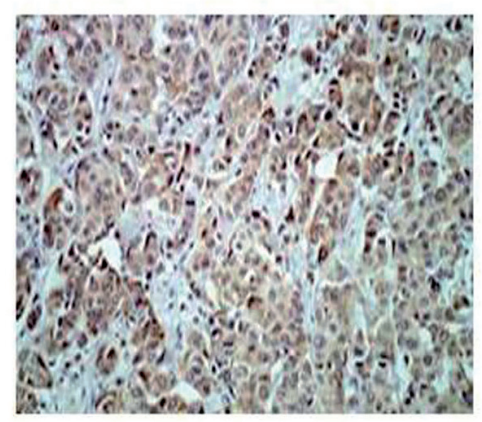

G

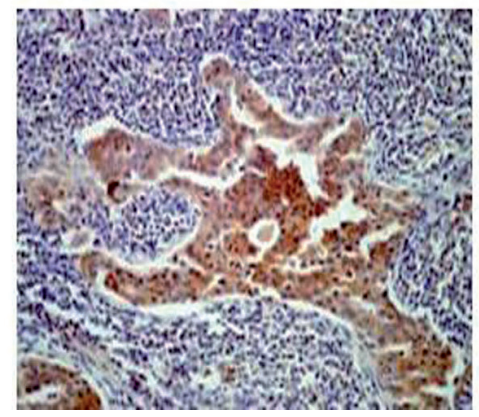

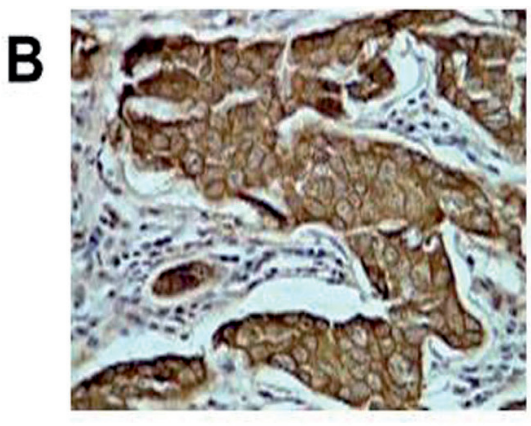
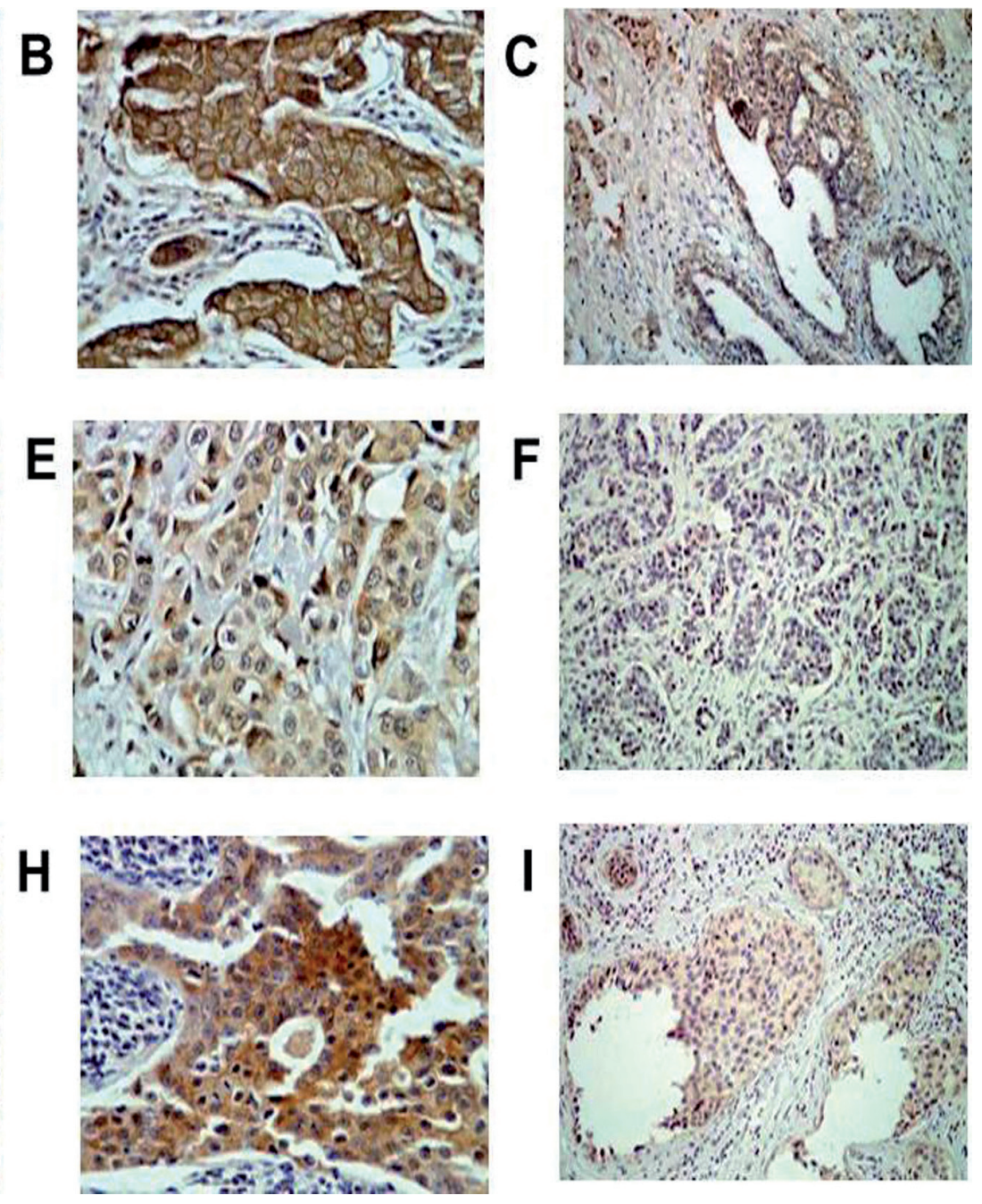

Figure 4. Immunohistochemical detection of EMT markers in breast cancer cases. A, B. Positive expression of E-cadherin $(\times 200, \times 400)$ C. Negative expression of E-cadherin $(\times 200)$ D, E. Positive expression of vimentin $(\times 200, \times 400)$ F. Negative expression of vimentin $(\times 200)$ G, H. Positive expression of $\beta$-catenin $(\times 200, \times 400)$ I. Negative expression of $\beta$-catenin $(\times 200)$ 
Table 3. The association between MAGE-A, EMT markers and clinical pathological features of breast cancers

\begin{tabular}{|c|c|c|c|c|c|c|c|c|c|c|c|c|c|}
\hline \multirow[t]{2}{*}{ Groups } & \multirow[t]{2}{*}{$\mathrm{N}$} & \multicolumn{2}{|c|}{ MAGE-A } & \multirow[t]{2}{*}{$P^{a}$} & \multicolumn{2}{|c|}{ Vimentin } & \multirow[t]{2}{*}{$P^{a}$} & \multicolumn{2}{|c|}{ E-cadherin } & \multirow[t]{2}{*}{$P^{a}$} & \multicolumn{2}{|c|}{$\beta$-catenin } & \multirow[t]{2}{*}{$P^{a}$} \\
\hline & & + & - & & + & - & & + & - & & + & - & \\
\hline Age & & & & 0.983 & & & 0.730 & & & 0.835 & & & 0.197 \\
\hline$<50$ & 53 & 26 & 27 & & 19 & 34 & & 46 & 7 & & 46 & 7 & \\
\hline$\geq 50$ & 67 & 33 & 34 & & 22 & 45 & & 59 & 8 & & 52 & 15 & \\
\hline Menopausal state & & & & 0.717 & & & 0.951 & & & 0.730 & & & 0.700 \\
\hline Premenopause & 59 & 30 & 29 & & 20 & 39 & & 51 & 8 & & 49 & 10 & \\
\hline Postmenopause & 61 & 29 & 32 & & 21 & 40 & & 54 & 7 & & 49 & 12 & \\
\hline Tumor size $(\mathrm{cm})$ & & & & 0.102 & & & 0.471 & & & 0.580 & & & 0.412 \\
\hline$\leq 2$ & 64 & 27 & 37 & & 20 & 44 & & 55 & 9 & & 54 & 10 & \\
\hline$>2$ & 56 & 32 & 24 & & 21 & 35 & & 50 & 6 & & 44 & 12 & \\
\hline Axillary lymphonode & & & & $<0.001$ & & & 0.009 & & & 0.012 & & & 0.228 \\
\hline+ & 68 & 45 & 23 & & 30 & 38 & & 64 & 4 & & 53 & 15 & \\
\hline- & 52 & 14 & 38 & & 11 & 41 & & 41 & 11 & & 45 & 7 & \\
\hline TNM stage & & & & 0.687 & & & 0.434 & & & 0.676 & & & 0.133 \\
\hline I & 37 & 16 & 21 & & 10 & 27 & & 33 & 4 & & 31 & 6 & \\
\hline II & 58 & 30 & 28 & & 23 & 35 & & 49 & 9 & & 50 & 8 & \\
\hline III & 25 & 13 & 12 & & 8 & 17 & & 23 & 2 & & 17 & 8 & \\
\hline Pathological type & & & & 0.446 & & & 0.118 & & & 0.050 & & & 0.110 \\
\hline Invasive ductal & 92 & 47 & 45 & & 28 & 64 & & 84 & 8 & & 78 & 14 & \\
\hline Others & 28 & 12 & 16 & & 13 & 15 & & 21 & 7 & & 20 & 8 & \\
\hline Bloodvessel invasion & & & & 0.204 & & & 0.090 & & & 0.320 & & & 0.238 \\
\hline+ & 46 & 26 & 20 & & 20 & 26 & & 42 & 4 & & 40 & 6 & \\
\hline- & 74 & 33 & 41 & & 21 & 53 & & 63 & 11 & & 58 & 16 & \\
\hline ER & & & & 0.027 & & & 0.001 & & & $<0.001$ & & & $<0.001$ \\
\hline+ & 90 & 39 & 51 & & 23 & 67 & & 85 & 5 & & 84 & 6 & \\
\hline- & 30 & 20 & 10 & & 18 & 12 & & 20 & 10 & & 15 & 15 & \\
\hline $\mathrm{PR}$ & & & & $<0.001$ & & & $<0.001$ & & & 0.656 & & & 0.011 \\
\hline+ & 82 & 31 & 51 & & 15 & 67 & & 73 & 9 & & 72 & 10 & \\
\hline- & 38 & 28 & 10 & & 26 & 12 & & 32 & 6 & & 26 & 12 & \\
\hline Ki-67 & & & & 0.078 & & & 0.369 & & & 0.358 & & & 0.307 \\
\hline$\leq 14 \%$ & 12 & 3 & 9 & & 6 & 6 & & 9 & 3 & & 8 & 4 & \\
\hline$>14 \%$ & 108 & 56 & 52 & & 35 & 73 & & 96 & 12 & & 90 & 18 & \\
\hline HER-2 & & & & 0.017 & & & 0.244 & & & 0.350 & & & 1.000 \\
\hline+ & 25 & 7 & 18 & & 11 & 14 & & 20 & 5 & & 20 & 5 & \\
\hline- & 95 & 52 & 43 & & 30 & 65 & & 85 & 10 & & 78 & 17 & \\
\hline P53 & & & & 0.367 & & & 0.269 & & & 0.097 & & & 0.077 \\
\hline- & 64 & 29 & 35 & & 19 & 45 & & 59 & 5 & & 56 & 8 & \\
\hline+ & 56 & 30 & 26 & & 22 & 34 & & 46 & 10 & & 42 & 14 & \\
\hline TOPO II & & & & 0.160 & & & 0.971 & & & 0.096 & & & 0.803 \\
\hline- & 13 & 4 & 9 & & 5 & 8 & & 9 & 4 & & 9 & 4 & \\
\hline+ & 107 & 55 & 52 & & 36 & 71 & & 96 & 11 & & 89 & 18 & \\
\hline Histology grade & & & & 0.001 & & & 0.090 & & & 0.009 & & & $<0.001$ \\
\hline $\mathrm{I}$ & 37 & 9 & 28 & & 8 & 29 & & 35 & 2 & & 34 & 3 & \\
\hline II & 58 & 35 & 23 & & 21 & 37 & & 53 & 5 & & 51 & 7 & \\
\hline III & 25 & 15 & 10 & & 12 & 13 & & 17 & 8 & & 13 & 12 & \\
\hline
\end{tabular}

a Pearson's $\chi^{2}$ test or Continuity Corrected Pearson's $\chi^{2}$ test or Fisher's Exact Test. 
Table 4. Relationship between MAGE-A and EMT markers.

\begin{tabular}{lccccc}
\hline EMT Markers & & $\mathrm{N}$ & \multicolumn{2}{c}{ MAGE-A } & \multirow{2}{*}{$P$} \\
\cline { 3 - 5 } & & & + & - & \\
\hline vimentin & + & 41 & 30 & 11 & $<\mathbf{0 . 0 0 1}$ \\
\multirow{3}{*}{ E-cadherin } & - & 79 & 29 & 50 & \\
& + & 105 & 47 & 58 & $\mathbf{0 . 0 1 1}$ \\
$\beta$ & - & 15 & 12 & 3 & \\
-catenin & + & 98 & 44 & 54 & $\mathbf{0 . 0 4 8}$ \\
& - & 22 & 15 & 7 & \\
\hline
\end{tabular}

MAGE-A positive cases were more likely to undergo EMT. Since EMT and high expression of MAGE-A are all responsible for high aggressiveness of malignancies, we raise the hypothesis that MAGE-A may be linked to EMT. To test our assumption, we analyzed the relationship between MAGE-A and EMT markers. The results were documented in Table 4. As expected, MAGE-A was significantly associated with vimentin-positive $(P=0.000)$, but inversely correlated with $\mathrm{E}$ cadherin-positive $(P=0.011)$ as well as $\beta$-catenin-positive cases $(P=0.048)$. The results demonstrated that MAGE-A positive cases were more inclined to undergo EMT.

Suppression of MAGE-A inhibited metastasis of MDAMB-231 cells. MAGE-A was down-regulated in highly metastatic phenotype breast cancer cell line-MDA-MB-231 via siRNA transfection to gain insight into the roles of MAGE-A in breast cancer metastasis. MAGE-A1, 2, 3, 4, 6, 12 were all knocked down in varying degrees confirmed by RT-PCR analyses (Figure 5). We observed that MAGE-A downregulation did not transform the spindle-like morphology of MDA-MB-231 cells to obvious epithelioid structure. However, the migratory and invasive capabilities of MAGE-A depletion

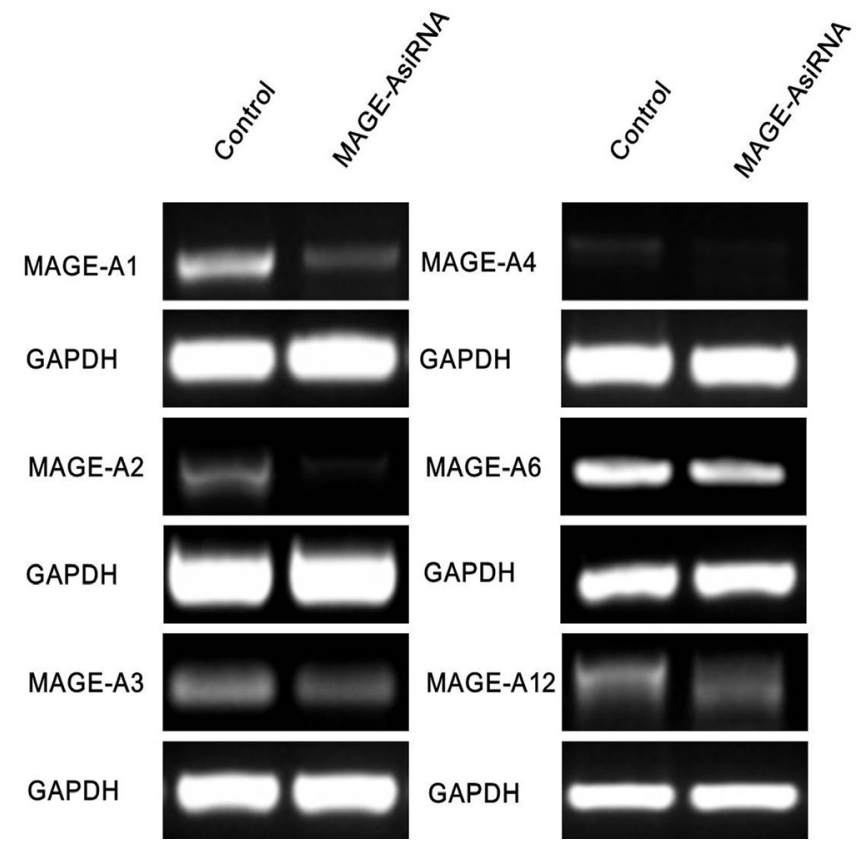

Figure 5. RT-PCR confirmation of decreased MAGE-A expression by siRNA transfection in MDA-MB-231 cell line.

cells were remarkably reduced as compared with the control cells (Figure 6, 7). Hence, MAGE-A expression was predictive of high potential to metastasis in aggressive breast cancer phenotypes.

Decrease in MAGE-A raised E-cadherin and $\beta$-catenin and reduced vimentin and $\mathrm{N}$-cadherin. Based on the correlation between MAGE-A expression and metastasis of breast
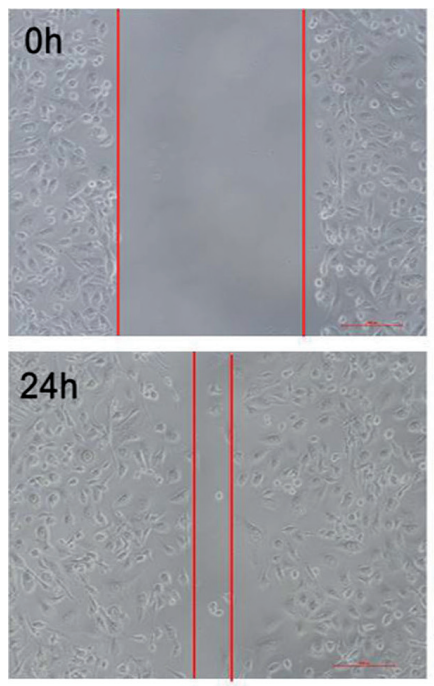

Control
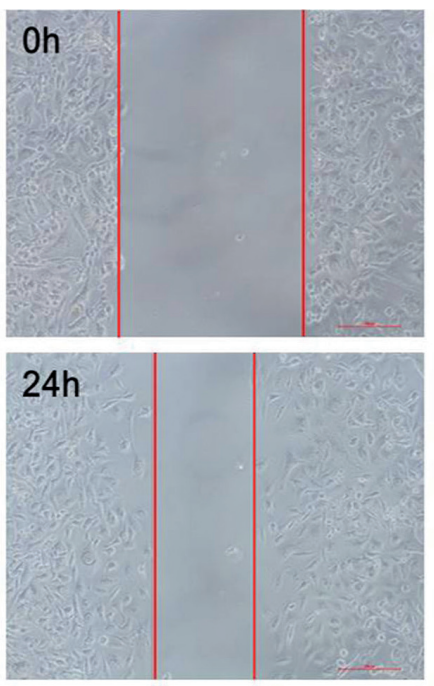

MAGE-A siRNA

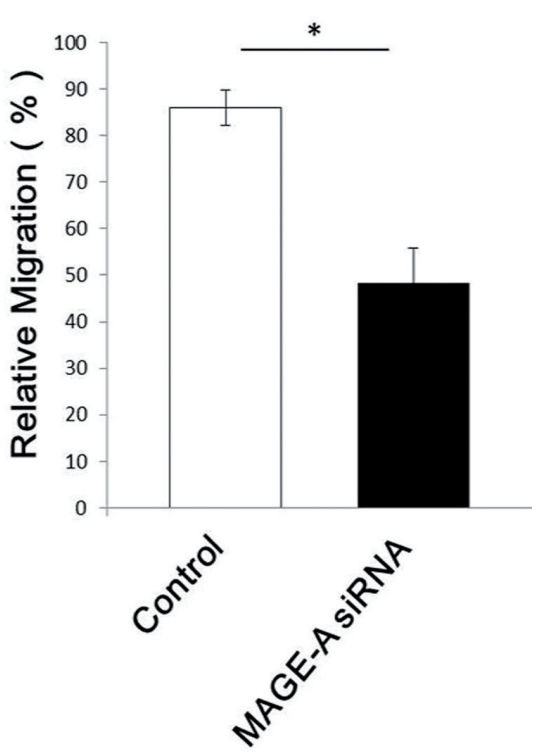

Figure 6. Scratch assay about migratory capability of MDA-MB-231 cells with MAGE-A down-regulation. ${ }^{*}, P<0.05$ 


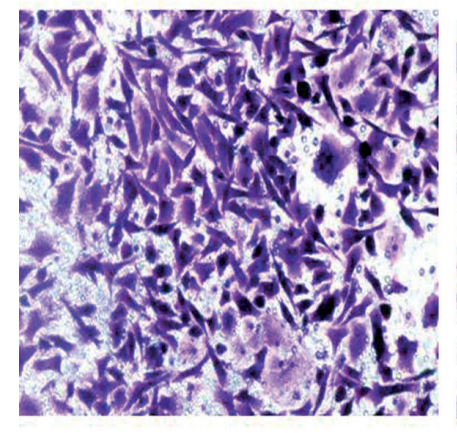

Control

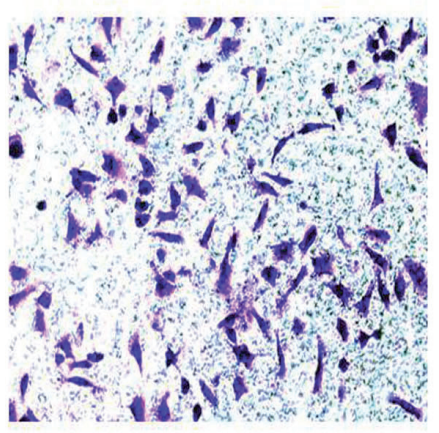

MAGE-A siRNA

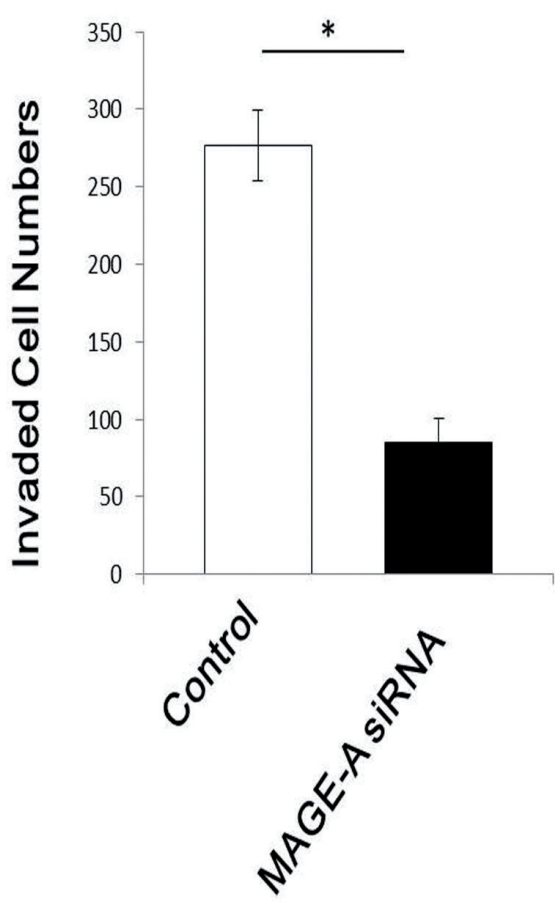

Figure 7. Transwell invasion assay about invasion of MDA-MB-231 cells with MAGE-A down-regulation. ${ }^{\star}, P<0.05$

cancer as well as the crucial role of EMT in cancer metastasis, we assessed the expression of epithelial and mesenchymal markers in MDA-MB-231 using real-time PCR. Intriguingly, the epithelial markers E-cadherin and $\beta$-catenin were evidently enhanced with a concomitant decrease in mesenchymal markers vimentin and N-cadherin (Figure 8). Since decline in epithelial markers and elevation in mesenchymal markers are hallmarks of EMT, we concluded that MAGE-A expres- sion may partially regulate EMT of MDA-MB-231. During EMT, MMPs are activated leading to extracellular matrix degradation and tumor cells metastasis. Our data showed that MMP9 remarkably decreased with MAGE-A down-regulation confirming the inhibition of metastasis caused by reduced MAGE-A expression (Figure 8).

MAGE-A regulated the expression of transcription factors in EMT. Snail, Slug, ZEB1 and ZEB2 are well-known
A

Control

MAGE-A siRNA

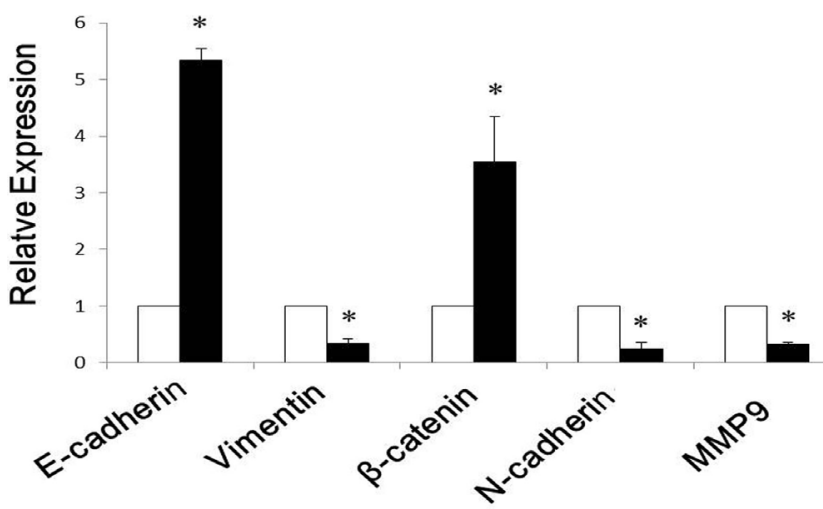

Figure 8. Real-time qPCR analyses of the epithelial markers E-cadherin, $\beta$-catenin and the mesenchymal markers vimentin, $\mathrm{N}$-cadherin, and MMP9. *, $P<0.05$
B

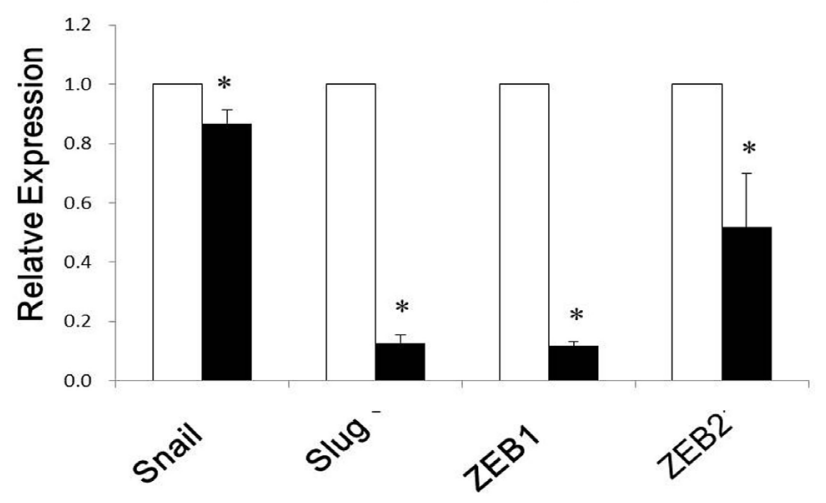

Figure 9. Real-time qPCR analyses of transcriptional factors of EMT Snail, Slug, ZEB1 and ZEB2. ${ }^{*}, P<0.05$ 
transcriptional factors of EMT. When EMT occurs, they will be activated and repress the promoter activation of E-cadherin. In order to investigate the impact of MAGE-A on EMT, expression profile of Snail, Slug, ZEB1 and ZEB2 were also analyzed. As shown in Figure 9, expression of the transcriptional factors were significantly down-regulated in MAGE-A loss group relative to the control cells, which suggested that MAGE-A could control EMT in part via regulation of transcriptional factors activated during EMT in MDA-MB-231.

\section{Discussion}

Due to lacking of effective treatment target and high aggressiveness, it is urgent to research on the mechanism of metastasis and explore new oncogenes responsible for invasion of TNBC. EMT has been recognized as the key for cancer metastasis, thus, it is essential to correlate oncogenes with EMT and provide basis for new therapeutic options. MAGE-A is a member of CTAs characteristic with restricted expression in germline cells and aberrant expression in a variety of cancers of disparate origins [18-19]. It is often coordinated [33] and related to aggressive cancer types [34-35] and poor clinical prognosis [36]. To this end, we put forward that MAGE-A may be an important contributor to EMT of TNBC.

We firstly analyzed the expression pattern of MAGE-A in 120 breast cancer cases and 10 tumor-free samples. The results showed that MAGE-A was specifically expressed in neoplastic samples with a percentage of $49.17 \%$. Chen et al [37] showed $17 \%$ of MAGE-A-positive cases and Kavalar et al [38] observed $64.2 \%$ of MAGE-A -expressed cases. The differences may be due to the diverse primary antibodies and scoring methods we used. We also analyzed the expression of MAGE-A in different subtypes. As expected, cases from TN group accounting for the highest proportion of MAGE-A bearing cases (76.47\%), followed by HER-2 enriched set (53.85\%) and Luminal set (43.33\%). A series of studies have been committed to evaluate MAGE-A expression in breast cancer cases with specific biomarkers. Curigliano et al [27] assessed expression of MAGE-A in $50 \mathrm{ER}(+) / \mathrm{HER}-2(-)$ and $50 \mathrm{TN}$ cases by IHC method. They found $32 \% \mathrm{TN}$ cases with higher intensity of MAGE-A, while $18 \% \mathrm{ER}(+)$ cases were positive for MAGE-A with lower intensity. According to Chen et al [45], the frequency of MAGE-A in ER-negative set was $24.5 \%$ which was higher compared to ER (+) cases. The specific expression pattern of MAGE-A in different breast cancer subtypes make it another biomarker for breast cancer classification. Moreover, the relative high prevalence of MAGE-A is believed to be another reason for aggressiveness of TNBC.

Then, we correlated MAGE-A with clinical pathological indicators. We showed that MAGE-A was markedly associated with ER (-), PR (-), and HER-2 (-), which demonstrated that MAGE-A expression is actually associated with TN set further. Also, MAGE-A-positive cases were often with high histological grade and metastatic axillary lymph nodes, which strengthened the association between MAGE-A and cancer progression. According to some studies, MAGE-A proteins have to do with negative hormone receptor status, high histologic grade [37, 39], large tumor size $(\geq 2 \mathrm{~cm})$ [36], positive sentinel lymph nodes (SLN) [40], high Ki-67 score [27] and HER-2 negativity. Notably, MAGE-A expression is contributed to unfavorable outcomes and cancer development.

EMT is a key mechanism for the metastasis of malignant tumors [41-44]. Down-regulation of epithelial markers and elevation in mesenchymal markers are hallmarks of EMT [4549]. In this study, we analyzed the expression of well-known EMT markers in breast cancers and related them to pathologi$\mathrm{cal}$ indexes. We concluded that vimentin was more frequent in TNBC compared to E-cadherin and $\beta$-catenin which were prevalent in Luminal set. In Hoiseon's [50] study, 25.4\% of TN-type patients were vimentin-positive, and decreased Ecadherin expression was seen in $16.7 \%$ TNBC. However, the corresponding data was $4.1 \%$ and $11.8 \%$ in hormone receptorpositive cases, respectively. Nami et al [11] reported that the expression of vimentin was significantly higher in TN cases relative to other subtypes immunohistochemically. Seema et al [29] found E-cadherin was predominantly positive in nonTNBC, whereas significant increased expression of vimentin was observed in TN cases. Our result was in accordance with the data listed above, which indicated that EMT is certainly a common phenomenon in TNBC. We also assessed relationship between EMT markers and pathological indexes. We found that vimentin expression was associated with ER (-) PR $(-)$ lymph nodes $(+)$ cases, whereas E-cadherin was inversely linked to ER (-), positive lymph nodes and high histological grade. Moreover, $\beta$-catenin was significantly related to ER $(+)$, PR (+) and lower histological grade. A battery of studies uncovering the similar results $[11,50]$ implied the actual association between EMT and TNBC.

We also found that MAGE-A was significantly associated with vimentin $(+)$ and E-cadherin $/ \beta$-catenin $(-)$ cases, which suggested that MAGE-A may be correlated with EMT. Accordingly, in view of the crucial role of EMT in cancer metastasis, we assumed that MAGE-A is more likely to be responsible for EMT of TNBC. According to our results, decreased MAGE-A significantly inhibited migration and invasion of MDA-MB-231 and led to increase in epithelial markers and down-regulation of mesenchymal markers. As we all know EMT is marked by loss of epithelial markers and enhancement in mesenchymal indicators. The results we obtained demonstrated that MAGE-A down-regulation may reverse EMT of MDA-MB-231 cell line. The conclusion was further verified by the decreased transcriptional factors activated during EMT in the context of MAGE-A downregulation. Though no significant changes in morphology of MDA-MB-231, these results informed us that MAGE-A can regulate EMT of TNBC in part. Degradation of extra cellular matrix by MMPs is the key for cancer metastasis. When EMT occurs, MMPs are activated to facilitate degradation of extra cellular matrix. In this study we observed that MAGE-A downregulation resulted in MMP9 reduction indicating the positive role of MAGE-A 
in cancer metastasis. In consequence, high level of MAGE-A is another reason for high metastasis and bad prognosis of TNBC. To our knowledge, we provide the first evidence that MAGE-A expression is correlated with EMT in TNBC providing a new clue for therapeutic options. By far, no study refers to association between MAGE-A members and EMT in cancers. However, expression of MAGE-C2 was clarified to be responsible for breast cancer metastasis and was able to induce EMT in breast cancer cell lines [51]. The mechanism underlying the event was not elucidated yet. Nevertheless, concerning the positive function of MAGE-A in breast cancer progression, it is reasonable to believe that MAGE-A is a pivotal contributor to EMT of TNBC.

\section{Conclusions}

In conclusion, we showed that MAGE-A is highly expressed in TNBC and associated with factors predicating highly metastasis. What's more, MAGE-A has an impact on TNBC progression via the regulation of EMT. Together, these conclusions provide a new clue for EMT-related oncogene and yield new insight into cancer metastasis and novel avenues for treatment. Further studies should be done to explore the exact mechanism and signals involved in MAGE-A related EMT.

\section{References}

[1] ANDERSON KN, SCHWAB RB AND MARTINEZ, ME. Reproductive risk factors and breast cancer subtypes: a review of the literature. Breast Cancer Res Treat. 2014; 144: 1-10. http://dx.doi.org/10.1007/s10549-014-2852-7

[2] NIELSEN TO, HSU FD, JENSEN K, CHEANG M, KARACA $\mathrm{G}$, et al. Immunohistochemical and clinical characterization of the basal-like subtype of invasive breast carcinoma. Clin Cancer Res. 2004; 10: 5367-5374. http://dx.doi.org/10.1158/10780432.CCR-04-0220

[3] GUPTA PB, MANI S, YANG J, HARTWELL K AND WEINBERG RA. The evolving portrait of cancer metastasis. Cold Spring Harb Symp Quant Biol. 2005; 70: 291-297. http:// dx.doi.org/10.1101/sqb.2005.70.033

[4] LIVASY CA, KARACA G, NANDA R, TRETIAKOVA MS, OLOPADE OI, et al. Phenotypic evaluation of the basal-like subtype of invasive breast carcinoma. Mod Pathol. 2006; 19: 264-271. http://dx.doi.org/10.1038/modpathol.3800528

[5] REIS-FILHO JS AND TUTT AN. Triple negative tumours: a critical review. Histopathology. 2008; 52: 108-18. http:// dx.doi.org/10.1111/j.1365-2559.2007.02889.x

[6] DE RUIJTER TC, VEECK J, DE HOON JP, VAN ENGELAND M AND TJAN-HEIJNEN VC. Characteristics of triple-negative breast cancer. J Cancer Res Clin Onco. 2011; 137: 183-192. http://dx.doi.org/10.1007/s00432-010-0957-x

[7] GAVERT N AND BEN-ZE'EV A. Epithelial-mesenchymal transition and the invasive potential of tumors. Cell press 2008. 2008; 199-209.

[8] HECTOR P, DAVID O AND AMPARO C. Snail, ZEB and bHLH factors in tumor progression: an alliance against the epithelial phenotype? Nat. Rev. Cancer. 2007; 7: 415-428. http://dx.doi.org/10.1038/nrc2131

[9] POLYAK K AND WEINBERG RA. Transitions between epithelial and mesenchymal states: acquisition of malignant and stem cell traits. Nat Rev Cancer. 2009; 9(4): 265-273. http:// dx.doi.org/10.1038/nrc2620

[10] GUNASINGHE NP, WELLS A, THOMPSON EW AND HUGO HJ. Mesenchymal epithelial transition (MET) as a mechanism for metastatic colonization in breast cancer. Cancer Metastasis Rev. 2012; 31(3: 469-478.

[11] NAMI Y, ERIKO T, HIROYUKI K, YUICHI H, KENJI T, et al. Vimentin as a poor prognostic factor for triple-negative breast cancer. J Cancer Res Clin Oncol. 2013; doi: 10.1007/s00432-013 -1376-6. http://dx.doi.org/10.1007/s00432-013-1376-6

[12] GUPTA GP AND MASSAGUE J. Cancer metastasis: building a framework. Cell. 2006; 127: 679-695. http://dx.doi. org/10.1016/j.cell.2006.11.001

[13] SAVAGNER P. Leaving the neighborhood: molecular mechanisms involved during epithelial-mesenchymal transition. Bio Essays. 2001; 23: 912-923. http://dx.doi.org/10.1002/ $\underline{\text { bies. } 1132}$

[14] THIERY JP. Epithelial-mesenchymal transitions in tumour progression. Nat Rev Cancer. 2002; 2: 442-454. http://dx.doi. org/10.1038/nrc822

[15] HERMAN J, VAN DER BRUGGEN P, LUESCHER IF, MANDRUZZATO S, ROMERO P, et al. A peptide encoded by the human MAGE-3 gene are presented by HLA-B44 induces cytolytic T lymphocytes that recognize tumor cells expressing MAGE3. Immunogenetics. 1996; 43: 377-383. http://dx.doi. org/10.1007/BF02199806

[16] BOON T. Old LJ: Cancer Tumor antigens. Curr Opin Immuno. 1997; 19: 681-683.

[17] COULIE PG, WEYNANTS P, LEHMANN F, HERMAN J, BRICHARD V, et al. Genes coding for tumor antigens recognized by human cytolytic T lymphocytes. J Immunother. 1993; 14: 104-109. http://dx.doi.org/10.1097/00002371-199308000$\underline{00004}$

[18] SCANLAN MJ, GURE AO, JUNGBLUTH AA, OLD LJ AND CHEN YT. Cancer/testis antigens: an expanding family of targets for cancer immunotherapy. Immunol Rev. 2002; 188: 22-32. http://dx.doi.org/10.1034/j.1600-065X.2002.18803.x

[19] SIMPSON AJ, CABALLERO OL, JUNGBLUTH A, CHEN YT AND OLD LJ. Cancer/testis antigens, gametogenesis and cancer. Nat Rev Cancer. 2005; 5: 615-625. http://dx.doi. org/10.1038/nrc1669

[20] CABALLERO OL AND CHEN YT. Cancer/testis (CT) antigens: potential targets for immunotherapy. Cancer Sci. 2009; 100: 2014-2021. http://dx.doi.org/10.1111/j.1349-7006 $.2009 .01303 . \mathrm{x}$

[21] BARKER PA AND SALEHI A. The MAGE proteins: emerging roles in cell cycle progression, apoptosis, and neurogenetic disease. J Neurosci Res. 2002; 67: 705-712. http://dx.doi. org/10.1002/jnr.10160

[22] DE PLAEN E, ARDEN K, TRAVERSARI C, GAFORIO JJ, SZIKORA, JP, et al. Structure, chromosomal localization, and expression of 12 genes of the MAGE family. Immunogenetics. 1994; 40: 360-369. http://dx.doi.org/10.1007/BF01246677 
[23] SANDRA L, RACHEL D, SIFANG Z, OLGA K, DANIE`LE G, et al. MAGE-A1 interacts with adaptor SKIP and the deacetylase HDAC1 to repress transcription. Nucleic Acids Res. 2004; 32: 4340-4350. http://dx.doi.org/10.1093/nar/ gkh735

[24] DUAN Z, DUAN Y, LAMENDOLA DE, YUSUF RZ, NAEEM R, et al. Overexpression of MAGE/GAGE genes in paclitaxel/doxorubicin-resistant human cancer cell lines. Clin Cancer Res. 2003; 9: 2778-2785.

[25] KASUGA C, NAKAHARA Y, UEDA S, HAWKINS C, TAYLOR MD, et al. Expression of MAGE and GAGE genes in medulloblastoma and modulation of resistance to chemotherapy. Laboratory investigation. J Neurosurg Pediatrics. 2008; 1: 305-313. http://dx.doi.org/10.3171/ PED/2008/1/4/305

[26] SUZUKI T, YOSHIDA K, WADA Y, HAMAI Y, SENTANI $\mathrm{K}$, et al. Melanoma-associated antigen-A1 expression predicts resistance to docetaxel and paclitaxel in advanced and recurrent gastric cancer. Oncol Rep. 2007; 18: 329-336 http://dx.doi. org/10.3892/or.18.2.329

[27] CURIGLIANO G, VIALE G, GHIONI M, JUNGBLUTH AA, BAGNARDI V, et al. Cancer-testis antigen expression in triple-negative breast cancer. Annals of Oncology.2011;22: 98-103. http://dx.doi.org/10.1093/annonc/mdq325

[28] THOMAS J, MAUD HWS, YAO-TSENG C, PRUDENCE AR, STEPHEN AB, et al. The Role of Cancer-Testis Antigens as Predictive and Prognostic Markers in Non-Small Cell Lung Cancer. PLOS ONE. 2013; 8: e67876. http://dx.doi. org/10.1371/journal.pone.0067876

[29] SEEMA S, FAZLUL HS, QURATULAIN A, SUDESHNA B, ZEINA AN, et al. Molecular Markers of Epithelial-to-Mesenchymal Transition Are Associated with Tumor Aggressiveness in Breast Carcinoma Translational Oncology. 2011; 4: 222-226

[30] DOMAGALA W, WOZNIAK L, LASOTA J, WEBER K, OSBORN M. Vimentin is preferentially expressed in high-grade ductal and medullary, but not in lobular breast carcinomas. Am J Pathol. 1990; 137: 1059-1064.

[31] GARCIA FERNANDEZ A, CHABRERA C, GARCIA FONT M, FRAILE M, LAIN JM, et al. Differential patterns of recurrence and specific survival between luminal A and luminal B breast cancer according to recent changes in the 2013 St Gallen immunohistochemical classification. Clin Transl Oncol. 2014; doi: 10. 1007/s12094-014-1220-8.

[32] GOLDHIRSCH A, WINER EP, COATES AS, GELBER RD, PICCART-GEBHART M, et al. Personalizing the treatment of women with early breast cancer: highlights of the St Gallen International Expert Consensus on the Primary Therapy of Early Breast Cancer 2013.Annals of Oncology. 2013; 24: 2206-2223. http://dx.doi.org/10.1093/annonc/mdt303

[33] TAJIMA K, OBATA Y, TAMAKI H, YOSHIDA M, CHEN $\mathrm{YT}$, et al. Expression of cancer /testis (CT) antigens in lung cancer. Lung Cancer. 2003; 42: 23-33. http://dx.doi. org/10.1016/S0169-5002(03)00244-7

[34] SHIGEMATSU Y, HANAGIRI T, SHIOTA H, KURODA $\mathrm{K}, \mathrm{BABA} \mathrm{T}$, et al. Clinical significance of cancer/testis ntigens expression in patients with non-small cell lung cancer.
Lung Cancer. 2010; 68: 105-110. http://dx.doi.org/10.1016/j. lungcan.2009.05.010

[35] YOSHIDA N, ABE H, OHKURI T, WAKITA D, SATO M, et al. Expression of the MAGE-A4 and NY-ESO-1 cancer-testis antigens and $\mathrm{T}$ cell infiltration in non-small cell lung carcinoma and their prognostic significance. Int J Oncol. 2006; 28: 1089-1098. http://dx.doi.org/10.3892/ijo.28.5.1089

[36] SCANLAN MJ, SIMPSON AJG AND OLD LJ. The cancer/ testis genes: review, standardization, and commentary. Cancer Immun. 2004; 4: 1.

[37] YAO-TSENG C, DARA S. R, Rita C, Xi K. Z, Yunn-Yi C, et al. Multiple Cancer/Testis Antigens Are Preferentially Expressed in Hormone-Receptor Negative and High-Grade Breast Cancers. PLOS ONE. 2011; 6: e17876. http://dx.doi.org/10.1371/ journal.pone.0017876

[38] KAVALAR R, SARCEVIC B, SPAGNOLI GC, SEPAROVIC V, SAMIJA M, et al. Expression of MAGE tumour-associated antigens is inversely correlated with tumour differentiation in invasive ductal breast cancers: an immunohistochemical study. Virchows Arch. 2001; 439: 127-131. http://dx.doi. org/10.1007/s004280100421

[39] MAHA A, CLARA-MARIA S, AHMED H, PASCALE $P$ AND DANILA V. Expression of MAGE-A3/6 in Primary Breast Cancer is Associated with Hormone Receptor Negative Status, High Histologic Grade, and Poor Survival. J Immunother. 2014; 37: 73-76. http://dx.doi.org/10.1097/ CJI.0000000000000013

[40] WASCHER RA, BOSTICK PJ, HUYNH KT, TURNER R, QI K, et al. Detection of MAGE-A3 in breast cancer patients sentinel lymph nodes. British Journal of Cancer. 2001; 85: 1340-1346. http://dx.doi.org/10.1054/bjoc.2001.2079

[41] VESUNA F, VAN DIEST P, CHEN JH AND RAMAN V. Twist is a transcriptional repressorof E-cadherin gene expression in breast cancer. Biochem Biophys Res Commun. 2008; 367: 235-241. http://dx.doi.org/10.1016/j.bbrc.2007.11.151

[42] HOLLIER BG, EVANS K AND MANI SA. The epithelial-to-mesenchymal transition and cancer stem cells: a coalition against cancer therapies. J Mammary Gland Biol Neoplasia. 2009; 14: 29-43. http://dx.doi.org/10.1007/s10911009-9110-3

[43] KONG D, LI Y, WANG Z AND SARKAR FH. Cancer stem cells and epithelial-to-mesenchymal transition (EMT) - phenotypic cells: are they cousins or twins? Cancers (Basel). 2011; 3: 716-729. http://dx.doi.org/10.3390/cancers30100716

[44] TAKEBE N, WARREN RQ AND IVY SP. Breast cancer growth and metastasis: interplay between cancer stem cells, embryonic signaling pathways and epithelial-to-mesenchymal transition. Breast Cancer Res. 2011; 13: 211. http://dx.doi. org/10.1186/bcr2876

[45] BEHRENS J, LOWRICK O, KLEIN-HITPASS L AND BIRCHMEIER W. The E-cadherin promoter: functional analysis of a G C-rich region and an epithelial cell-specific palindromic regulatory element. Proc. Natl Acad. Sci. USA. 1991; 88: 11495-11499. http://dx.doi.org/10.1073/ pnas.88.24.11495

[46] BIRCHMEIER W, BEHRENS J, WEIDNER KM, FRIXEN UH AND SCHIPPER J. Dominantand recessive genes 
involved in tumor cell invasion. Curr. Opin. Cell Biol. 1991; 3: 832-840. http://dx.doi.org/10.1016/0955-0674(91)90057-6

[47] JI X, WOODARD AS, RIMM DL AND FEARON ER. Transcriptional defects underlie loss of E-cadherin expression in breast cancer. Cell Growth Differ.1997; 8: 773-778.

[48] GIROLDI LA, BRINGUIER PP, DE WEIJERT M, JANSEN $\mathrm{C}$, VAN BOKHOVEN A, et al. Role of $\mathrm{E}$ boxes in the repression of E-cadherin expression. Biochem. Biophys. Res. Commun. 1997; 241: 453-458. http://dx.doi.org/10.1006/ bbrc.1997.7831

[49] HAJRA KM, JI X AND FEARON ER. Extinction of E-cadherin expression in breast cancer via a dominant re- pression pathway acting on proximal promoter elements. Oncogene. 1999; 18: 7274-7279. http://dx.doi.org/10.1038/ sj.onc. 1203336

[50] JEONG H, RYU Y-J, AN J, LEE Y AND KIM A. Epithelialmesenchymal transition in breast cancer correlates with high histological grade and triple-negative phenotype. Histopathology. 2012; 60 (6B): E87-E95. http://dx.doi. org/10.1111/j.1365-2559.2012.04195.X

[51] FAN Y, XINGCHUN Z, XIA M, TAO Z, XIAOJUN H, et al. MAGEC2, an epithelial-mesenchymal transition inducer, is associated with breast cancer metastasis. Breast Cancer Res Treat. 2014; 145: 23-32. http://dx.doi.org/10.1007/s10549-014 $\underline{-2915-9}$ 